\title{
Saami pulmakombed
}

\section{$\underline{\text { Aleksandra Antonova \& Jaan Sarv }}$}

Siinses artiklis tutvustatakse Koola poolsaare saamide traditsioonilist pulmakombestikku, mille kohta on seni kogutud ja avaldatud võrdlemisi vähe materjali. Kirjutise esimene osa esitab Aleksandra Antonova poolt ülestähendatud pulmakirjelduse, kusjuures erilist tähelepanu on pööratud traditsioonilisele terminoloogiale. Teises osas on ära toodud Jaan Sarve noodistused küllaltki haruldastest pulmalaulude salvestustest ühes kommentaaridega. Terminite tõlkimise, etümoloogiliste kommentaaride ning tekstide deshifreerimise juures on autorid teinud koostööd. Lugejal pole ülearune teada, et artikkel on valminud rohkem kui kümme aastat tagasi.

1.

Alljärgneva aluseks on Aleksandra Antonova ettekanne teaduslikul konverentsil «Muusika soomeugrilaste ja naaberrahvaste pulmakommetes» Tallinnas oktoobris 1986. a. See oli täienduseks Jaan Sarve ettekandele «Koola saamide kosjateemalised laulud» (Sarv 1986).

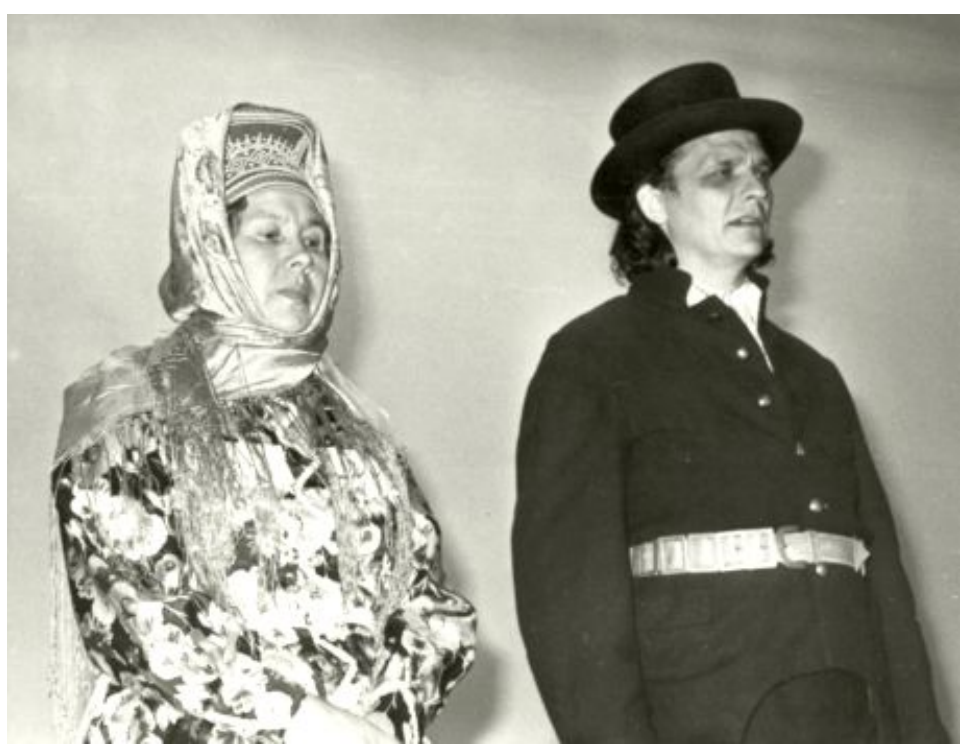

Autorid 1986. aasta oktoobris. Foto V. Kashkin 1986

Aleksandra Antonova on töötanud aastaid saami keele õpetajana Lujavre internaatkoolis, kus õpivad peamiselt saami põdrakasvatajate lapsed. Oma pedagoogikogemustele tuginedes alustas ta, siis juba Vene NFSV Haridusministeeriumi Rahvuskoolide Teadusliku Uurimise Instituudi teadusliku töötajana, uue saamikeelse aabitsa koostamist, mis ilmuski 1982. aastal (Antonova 1982). A. Antonova osales ka saami-vene sõnaraamatu töögrupis (SRS 1985). Ta on tegelnud saami rahvaloomingu, sealhulgas muinasjuttude üleskirjutamisega, kusjuures üks jutustajatest on olnud tema ema Marina Antonova. Järgnev ongi kirja pandud 1986. aasta juunikuus Marina Artem- 
jevna Antonova jutustuse järgi, kes on sündinud 1900. aastal Kildiru külas ja elas seal kuni 1929. aastani (praegu elab Lujavre asulas).

Saamikeelsetele terminitele on püütud leida vasted saami-eesti ühissõnavarast. Peab arvestama, et reglementeeritud saami kirjakeel on alles loomisel. Rahvasuus esineb üks ja sama sõna ka ühe murde piires sageli mitmes erinevas häälikulises variandis. Sageli on eri autorid ühte sõna erinevalt transkribeerinud. Itkose sõnaraamatu (KKS 1958) väga täpset foneetilist transkriptsiooni on siin lihtsustatud.

Pulmi pidasid saamid ainult talvisel ajal таллье оаркэсьм 1 , s.o novembri keskelt kuni suure paastuni². Suur paast algab 12 nädalatª enne lihavõtteid. See on kõige pikem paast. Mõned paastud on lühemad. Suure paastu ajal ei söödud liha ega lihatoite.

Saami noormees, kes oli otsustanud abielluda, pidi ajavahemikul, mis kestis 2,5 kuni 3 kuud, korda saatma palju: tuli leida pruut, käia kosjas ja kui kosjakaubad tehtud, siis ka pulmad pidada. Enne suurt paastu pidi kõik korras olema.

Suvel oli iga saami perekond tegevuses talviste toiduvarude hankimisega. Iga pere elas oma järve kaldal, tegeldes kalapüügi ja kalade kuivatamisega. Ka pere põdrakari oli läheduses suvistel karjamaadel. Põtru karjatasid nii noormehed kui neiud. Võis juhtuda, et põdrakarjas olles kohtas noormees teist karja, Jutustaja Marina kus karjuseks oli neiu. Nad tutvusid ja kui neiu meeldis, uuris Antonova. Foto J. Sarv noormees, kust külast ta pärit on, et hiljem sinna kosja sõita. Talveks tulid saamid kokku ühisesse talvekülla. ${ }^{5}$ Noormehed hakkasid naisevõtuplaane pidama. Kes ei leia oma külast meeldivat tüdrukut ja kel ka mujal kindlat kandidaati pole, sõidab sõpradega naaberkülla pruuti otsima.

Tutvuda võidi ka cnppnэppmэcsm ${ }^{6}$, majas, kuhu noorsugu kogunes tantsima ja mängima. Tantsuõhtuid korraldati külas talvisel ajal väga sageli, peaaegu igal õhtul.

Kui on leitud südamelähedane tüdruk, saadab noormees aega viitmata tema juurde kosilased $^{7}$. Kosjateele lähevad koos peigmehega tema vanemad ja kaasa kutsutakse veel keegi sugulastest.

Väljast on kuulda kellukeste helinat. Pererahvas läheb välja vaatama, kes külla tuleb. Kui on võõrad inimesed, teisest külast, aga siin peres on tütreid, siis on kohe selge, et kosilased tulevad. Või siis astuvad majja peoriides inimesed oma külast ja nende hulgas veel mõni noormees, jälle on kõik sõnadeta selge.

Pererahvas palub sisse tulla, pakub istet. Kosilastel on tingimata kaasas oma toidumoon - viin ja pähklid. Miks just pähklid, need ju põhjamaal ei kasva, see on omamoodi mõistatus. Kui on külakosti maitstud, hakkab pruudi ema rääkima umbes nii: «Viina jõime ära, pähklid on otsas, aga millega me külakosti eest tasume?»

Nüüd ütlevad kosilased: «Meil on poeg ja teil on tütar. Kuidas siis on? Ehk saame kaubale?» 
Või hoopis nii: «Kas me tõesti kokku ei lepi? Me oleme kaugelt tulnud, pikk tee väsitas ära.»

Ja kui paistab, et ka noored omavahel sobivad, siis öeldakse: «Kui juba neiu läheb ja noormees võtab, mis siis meilgi üle jääb muud, kui nõus olla.»

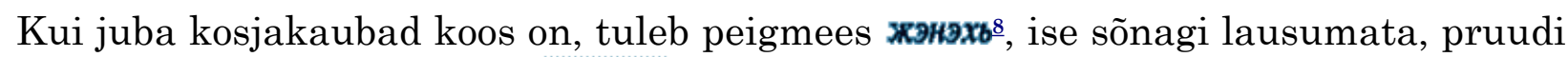
juurde ja seob talle siidrätiku pйссэщ 9 kaela. Siduda tuleb rätik umbsõlme, aga enne tõmbab peigmees rätikut kolm korda ümber neiu kaela. Kõik juuresolijad jälgivad, kuidas peigmees rätikut seob. Kui ta sidus nõrga sõlmega, on ta tulevase mehena lahke ja hea, kui aga tõmbas sõlme kõvasti kinni, on mees range ja karm või isegi kuri. Pruut roабсэсc10 peab seda rätikut kandma kogu elu. Peigmeest hakatakse sellest hetkest nimetama saami sõnaga коангэес11.

Mõlema poole vanemad lepivad omavahel kokku pulmade aja. Väga harva juhtus seda, et pulmad lükati edasi järgmise talveni.

Enne pulmi peab peigmees hankima tulevasele naisele abielunaise peakatte $\boldsymbol{u} \overline{\boldsymbol{a}} \boldsymbol{u} \boldsymbol{M} \boldsymbol{u}$ 12. Kui valmis tanu ei õnnestu osta ja oma ema või õde ei õmble, siis tuleb kellegi oskaja käest tellida. Pruut ei valmista endale erilisi pulmariideid, kuna tal on olemas peoriided, millega käiakse pidudel, tantsu- ja mänguõhtutel ja mis võetakse välja ainult pühade puhul. Kui neid riideid parajasti ei kasutata, pannakse nad väga hoolikalt kokku ja peidetakse kirstu või rahvuslikku riietehoidmise kotti $\boldsymbol{\beta}$ y̆cc 13 .

Kui pruut elab samas külas, käib peigmees vahel harva teda vaatamas, ka tantsima kutsumas. Küllaltki raske oli pruuti tantsu- ja mänguõhtutele kutsuda. Pruut - ja üldse ükski neiu - ei läinud ise tantsuõhtule. Tal oli alati palju tegemist. Vanemad lubasid tütreid ainult mõnikord tantsima minna. Kui noormees kutsuma tuli, ei andnud vanemad iga kord kohe luba. Enne pidi noormees vahel kolm-neli korda tüdrukut kutsumas käima, kuni lõpuks lubati.

Pulmapäeval viiakse pruut kõigepealt majja, kust teda pruudi-itkuga ära saadetakse - луйхькемпӭррьтэ14. See ei ole pruudi isakodu, vaid mõni naabermaja. Pruudi viib sinna tädi cũ ccb15. See aga pole ta tegelik tädi, pole sugulanegi, vaid ükskõik milline naine, kellega enne kokku on lepitud ja keda siis pulma kestel nii nimetatakse. Ta on üks pulma tähtsamaid tegelasi. Tädi riietab pruuti ja ise samal ajal laulab - itkeb pruuti. Pruut nutab kõige rohkem ja kõige kõvemini, samal ajal käivad sõbratarid, kümme või veel rohkemgi, pruudiga hüvasti jätmas. Tulevad tuppa, võtavad pruudil kaela ümbert kinni ja nutavad kaasa. Tädi laulab umbes selliste sõnadega: «Kuhu sa küll hakkad minema, kuidas sul seal elu läheb?» Võib-olla võrdleb ta sealset elu eluga isakodus, kui hea siin oli, et pruut peab jätma pehme aseme ja hellitused. Peab sõitma võõraste majja. Seal koheldakse teda halvasti. Muidugi hakkab pruut selliste sõnade peale nutma.

Pruudi riietusse kuuluvad järgmised esemed: eredavärviline sarafan, jakk, põll.16 Kõik need on siidist õmmeldud, eri värvi, aga toon-toonis sobitatud. Pähe jääb veel neiusoeng - üks pats - ja neiu peakate $\boldsymbol{n e ̄ p b e r s k}_{17}$.

Pärast itkemist paneb tädi pruudile pähe lahtise siidrätiku, mille narmad langevad näo ette. Läbi narmaste näeb pruut kõike toimuvat. Tädi viib pruudi vanematekoju, mida nüüd nimetatakse ëppmeмnэ̄ppm 18, maja, kus pruuti ja peigmeest keerutatakse. 
Siin istuvad tädi ja pruut tagatuppa eesriide taha ja jäävad peigmeest ootama.

Pruudi järele tullakse viiekesi - kõige ees tuleb $\$$ нна19, kellel on paremale õlale kinnitatud värvilisest lindist lehv. Tema järel tuleb ülikondao riietatud peigmees. Peigmehe järel tuleb veel üks noormees. Pärast neid tuleb «hobune» kutsariga21. Nad lähevad hanereas, üksteise vöökohast kinni hoides. Kõik trambivad välistrepil, tahavad sisse saada, aga uksel istub "valvur», mõni noorem poiss või tüdruk (pruudi noorem õde või vend), kes ei lase peigmeest sisse. Kutsar ajab hobust, hobune tõukab peigmeest ettepoole.

Nüüd küsib isamees valvurilt: «Me panime välja linnupaelad. Lind jäi paeltesse kinni, aga rebis need katki ja lendas koos silmusega minema. Kas te pole näinud, kuhu ta lendas?»

Valvur vastab: «Mul valutab kurk, ma ei saa rääkida.»

Isamees annab valvurile teed juua ja kordab küsimust. Valvur vastab: «Ma ei kuule, mul on kõrvad kurdid.» Saab uuesti lunamaksu ja ütleb, et tal valutavad silmad, et ta ei näe midagi.

Isamees võtab välja kaks hõbemünti, paneb need valvurile silmadele ja siis annab need talle - иалььмуваmъ22. Uuesti küsib isamees ja alles nüüd tõuseb valvur ja näitab, kuhupoole lind lendas - laseb nad järgmise ukse juurde. Ukse juures, mis viib eeskojast tarre, istub uus valvur. Kõik kordub nagu eelmisegi ukse juures. Ja olgu neid uksi majas kas või kümme, iga ukse juures istub valvur ja peab lunamaksu saama. Peigmees annab kõigile ühesuguse lunamaksu, ainult tee asemel võib olla midagi muud, mis parajasti selleks tarbeks kaasa võetud, mille poolest keegi, nagu öeldakse, rikas on.

Jõudnud viimaks eesriideni, mille taga istuvad pruut ja tädi, alustab isamees jälle kauplemist, nüüd juba tädiga. Ta esitab samu küsimusi, mis valvuritele. Tädi vastab samuti kui valvurid. Kui tädi oma lunamaksu kätte saab, teeb ta eesriide lahti ja näitab pruuti. Peigmees annab tädi kätte tanu ja võtab pruudil käest kinni. Nüüd peab tädi pruuti ja peigmeest kolm korda keerutama ja ütlema: «Võta oma pruut.» Siis lähevad nad pruudi vanemate juurde, kes noori ikooniga õnnistavad. Pruudikodunt sõidab noorpaar kirikusse. Neid saadab pulmarahvas, kuid mitte vanemad.

Kirikus paneb papp noorpaarile pähe kuldsed laulatuskroonid, loeb nende ees palveid, süütab küünlalaual kolm küünalt, võtab ühe käega noortel käest, noorikul paremast, peigmehel vasakust käest kinni ja talutab nii kolm korda ümber küünlalaua.

Nüüd läheb kombetalitus tädi kätte, kes punub pruudi patsi kaheks, paneb patsid pärjana ümber pea, teeb neist abielunaise soengu пуалмэх 23, paneb pähe tanu, katab selle uuesti rätiga kinni, nii et narmad langevad näo ette, ja ütleb peigmehele: «Võta oma noor naine koa6nэ24. Peigmees suudleb pruuti ja viib ta kirikust oma koju.

Pruudi vanemad lähevad sel ajal peigmehekoju ja võtavad koos peigmehe vanematega noorpaari ikoonidega vastu.

Noorpaar põlvitab vanemate ette. Nüüd õnnistab noorpaari peigmehe ema. Ta teeb ikooniga noorpaari selja kohal kolm ristimärki. Peale vanemate onnistust istub kogu pulmarahvas lauda. Et ruumid on kitsad, siis peavad külalised üsna tihedalt istuma. 
Isamees valab viina ja lubab kõigil toidu kallale asuda.

Valvurid - lapsed, kes pruudimajas ukse peal valvasid, - ronivad sel ajal maja katusele ja lasevad paela otsas läbi suitsuaugu mingi anuma alla, kuhu neilegi kosti ja võibolla ka raha pannakse, sest majja nad ju ei mahu. Peo lõpul käib isamees kandikuga suure puust saami vaagnaga - kõik külalised läbi. Külalised annavad mitmesuguseid kingitusi (raha, riiet). Kes tahab põtra kinkida, teeb leivast kuulikese, murrab tiku pooleks ja torkab nurgeti kuuli sisse nagu sarved, paneb kandikule ja ütleb, millise põdra ta kingib. Põder oli kõige hinnalisem kingitus. Enamasti kingiti noorpaarile emapõder, et oleks järelkasvu, et nende varandus kasvaks. Kes kingib lamba, see pistab leivakuulikese sisse ühe tiku.

Peigmehe ema ja isa kingivad pruudi emale valmis sarafani või riiet selle jaoks, sest ema kiigutas tütart põlvedel ja sarafan kulus. Saami hälli võttis ema tihti põlvedele: lapse söötmiseks, magama hällitamiseks ja muidu ka. Aga isale kingitakse aluspesu.

Pruut ei valmistanud mingeid erilisi kingitusi, kui, siis nahku, nahkadest tekke või patju, kõige vajalikumaid asju.

Kui on küllalt söödud-joodud, koristatakse lauad ja viiakse toast välja. Isamees kogub noored tantsima ja mängima. Kõige rohkem armastavad noored kadrilli tantsida. Seda võivad nad tantsida vahetpidamata kasvõi 12 korda järjest. Lõõtspillimehigi jätkus. Peaaegu iga noormees oskas lõotspilli mängida ja veel praegugi on 50-aastaste hulgas palju neid, kes seda oskavad.

Pruut kannab kolm päeva narmastega rätikut näo ees. Kolmandal päeval tuleb uuesti tädi ja võtab rätiku ära samal tunnil, millal papp noorpaari kirikus laulatas. Ta seob nüüd rätiku teistmoodi, paneb diagonaali mööda kokku ja seob tanu peale, kas otstega ette või siis eest risti ja otsad tagant uuesti kokku.

Kui pruut oli teisest külast, siis peeti pulmi külas, kus elas pruut. Pärast saadavad sugulased pruudi peigmehe külla ja seal peetakse pulmi uuesti. Kui kirikut pole ühes ega teises külas, peetakse pulmade teine pool selles külas, kus toimub laulatus.

Saamide pulmakombestik oli põhiolemuselt sarnane kõigis külades, kuid ei puudunud ka kohalikud detailid. Pulmad koosnesid järgmistest etappidest: pruudi valimine, kosjad, pruudi itketamine, laulatus, pulmapidu, mängud ja tantsud.

Itkemine on kindla pulmategelase, pruudi ehtija (tädi) zhanr. Oma laulus ei luba ta pruudile magusat elu. Laulus vastandatakse neiu elu isakodus elule äia ja ämma juures. Tädi nagu loeks pruudi mõtteid ja tundeid ning esitab need sõnades.

Kirjeldatud pulmakombestik oli tarvitusel käesoleva sajandi algusaastail. 1914. aastast alates ei olevat jutustaja sõnade kohaselt selle kombe järgi enam pulmi peetud. Jutustaja ise on abiellunud juba uue kombe kohaselt.

\section{2.}

Pulmalaulude kohta on andmeid napilt. Aleksandra Antonova, kes on kuulnud väga palju saami laule, pole kunagi kuulnud laulikut ütlemas, et ta laulab nüüd pulmalaulu. Ometi on 1977. aasta salvestiste hulgas (I. Bogdanov, J. Sarv) ka mõned pulmakombestikuga seostatavad laulud, näiteks Aleksandra Antonova ema Marina Antonova 
lauldud laul, millega sõbratarid pruuti laulatusele saadavad. 1986. aastal toimunud rahvamuusikakonverentsil Tallinnas näitasid ansambli «Oijar» liikmed stseene saami pulmast. Seal laulsid analoogilist laulu pruudi juuste palmitsemise juures Maria Zahharova ja Anissia Jurjeva. Pärast konverentsi palusime seda laulu ka linti laulda. Esialgu proovisid nad seda kahekesi laulda, siis aga jäi Anissia Jurjeva vait ja laskis Maria Zahharoval üksi lõpuni laulda. Kui laul otsa sai, seletasid nad tekkinud arusaamatust nii: «Sa laulsid isakoduga hüvastijätu sõnu, aga mina laulsin: tere, tere, kus kodu, mehe kodu.» Siit võib välja lugeda, et ka saami pulmades eksisteeris väljakujunenud laulutsükliga tseremoonia, mille kohta on võimalik andmeid leida rahva mälus säilinud laulutekstidest ka tänapäeval. Kaks saami pulmalaulu koos nootidega toob ära I. Travina oma raamatus "Саамские народные песни" (Travina 1987: 101-103, 140-141). Mõlemad laulud on salvestatud 1965. aastal Lujavres e Lovozeros ja kuuluvad kildini murdepiirkonda. Esimene neist kuulub kosjateemaliste laulude hulka, teine on pruudisaatmise itk. Mõlemal meloodial on ühisjooni allpoolesitatud esimese laulu meloodiaga.

Toome ära mõned pulmadega seostuvate laulude noodistused. Kõigepealt kõige värskem salvestis - Anissia Jurjeva lauldud pruudi ärasaatmise itk, salvestatud 1986. aasta oktoobris Eesti Raadios (J. Sarv).

\section{Mõrsja saatmise itk}

Laulab Anissia Jurjeva, pärit Lujavre (Lovozero) külast Murmanski obl (kildinisaami dialekt). Salvestatud Eesti Raadios 10. oktoobril 1986. Teksti dešifreeris Aleksandra Antonova, noodistas Jaan Sarv.
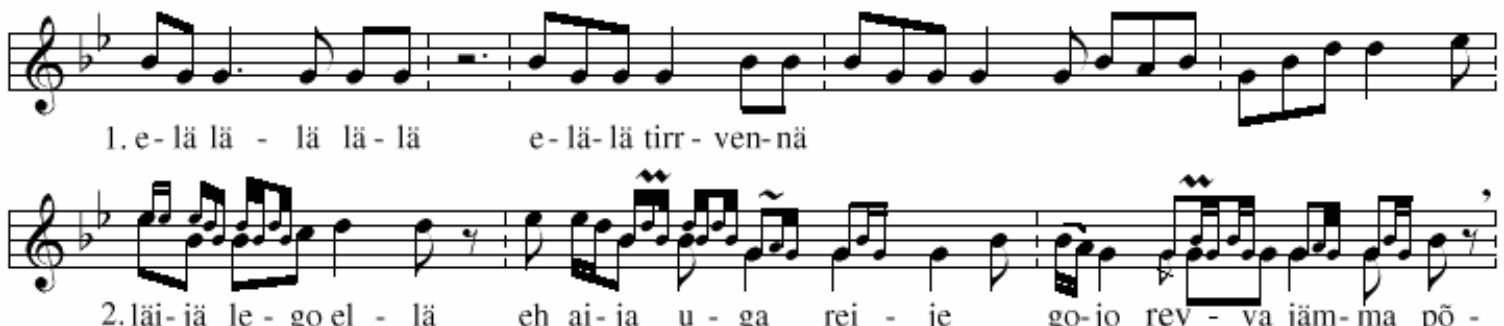

2. läi-jä le-goel - lä eh ai-ja u-ga rei - je

go-jo rev - va jäm-ma põ -

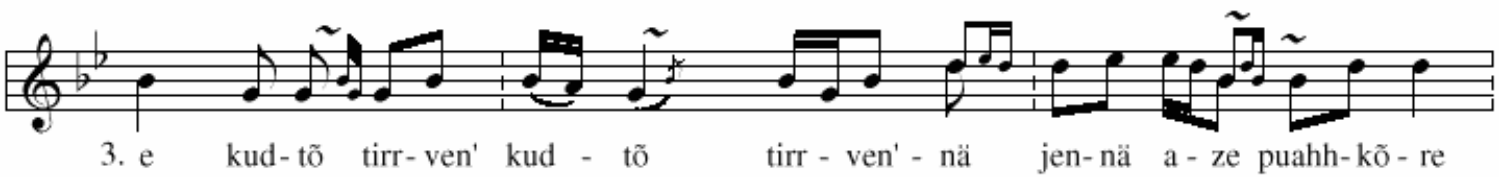




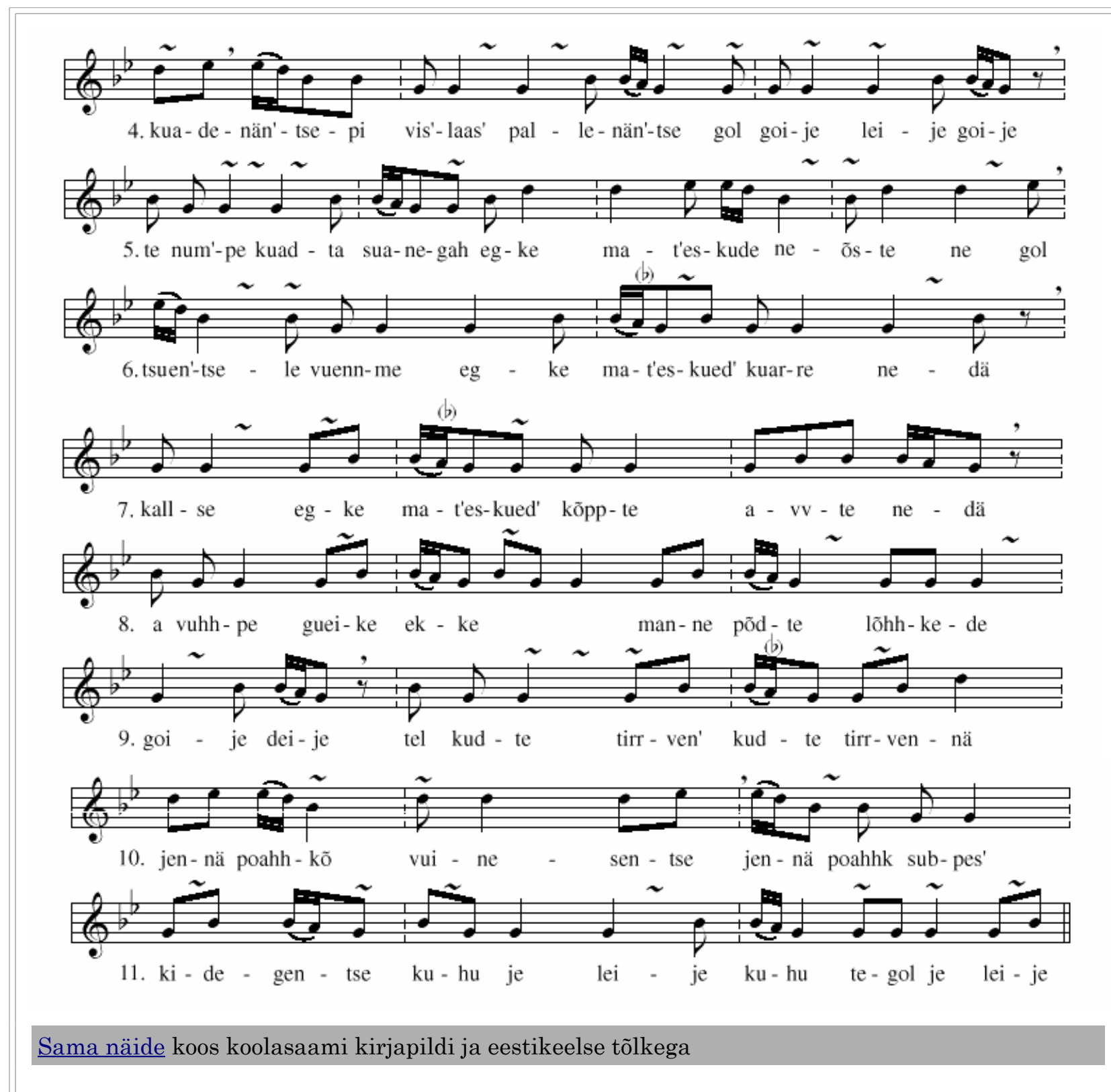

Laulu tekstiosa on esitatud kolmel real: esimesel noodistaja kuuldeline deshifreering, mis võimalikult täpselt vastab teksti silbilisele koosseisule. Kuigi seda teksti on saamikeelse deshifreeringu põhjal ühtlustatud, võib siin esineda erinevusi sõna- ja silbipiiri määramisel ja ka häälikute tajumisel. Teisel real esitatakse tekst Aleksandra Antonova deshifreeringus praegu loodavas saami kirjaviisis (slaavi shriftis lisamärkidega). Selles tekstis on esitamata (eriti laulu algusosas) muist asemantilisi silpe. Kolmandal real on antud teksti eestikeelne vaste. Selles on kasutatud võimalikult palju saami-eesti ühissõnavara, et lugeja paremini tajuks teksti semantilist struktuuri ja saaks seda võrrelda eesti rahvalaulude tekstiehitusprintsiipidega. Ometi peab arvestama, et seda teksti ei saa käsitleda reaalse tõlkena. Selleks erineb lauldav keel liialt kõneldavast ja üleskirjutamist võimaldavast tekstist. Kõrvuti asemantilise osisega esineb sõnade kuluvorme, ebamääraseid grammatilisi vorme, mis kõik raskendab tõlke korrektset vormistamist. 
Laul algab jutustamise keskelt ja peaaegu üminal, nii et osa noodistust ongi jäänud ilma tekstita.

Noodistuses on helivältused märgitud küllalt tinglikult, sageli vaid naabernootide vältustega võrreldes, sest esitusel puudub kindel taktimõõt ja ühtlane tempo. On selge, et helivältusi mõjutab loomulik kõnerütm, mis laulus on siiski mõnevõrra organiseeritum.

Teises noodireas on näitlikustamise huvides avatud esituse melismaatika, mida edaspidi märgitakse vaid pikema või lühema trillerimärgiga noodi kohal, kui kaunistus on silbi algul, ja nootide vahel, kui kaunistus esineb silbi teises pooles. Need kaunistused on idapoolsete saamide (kildini, turja murdepiirkond) lauludele tunnuslikud. Meie külalised suutsid ka ise teadlikult formuleerida nende kaunistuste iseloomu. Siiski vajab nii nende iseloomustus kui ka rahvalik ja teaduslik terminoloogia täpsustamist. Tavaliselt on kaunistused tertsi või sekundi ulatusega ja - erinevalt mõnede teiste laulustiilide kaunistusnootidest - väga konkreetse rütmilise jaotusega, mida on hea jälgida, kui kuulata salvestist näiteks poole aeglasemalt.

Sama tüüpi meloodiaga laulu pealkirjaga «Pulmalaul» («Svadebnaja») on 1928. aastal fonografeerinud Zinaida Evald ja Jevgeni Gippius. Laulab Dunja Matrjohhina. Vaharulli hoitakse praegu St. Peterburgi Fonogramm-arhiivis (Pushkini majas). Väga halvas seisukorras salvestist on sealses laboratooriumis restaureeritud. Kahjuks on muusikat kuulda siiski vaid väga fragmentaarselt. Teksti on võimatu deshifreerida.

\section{Pulmalaul}

Laulab Dunja Matrjohhina (koduküla teadmata). Fonografeerisid 1928. a Jevgeni Gippius ja Zinaida Evald (Фонограмархив Пуикинского дома, Ленинград, 1407 , XXVIII/28 No 3), noodistas Jaan Sarv. Teksti pole võimalik dešifreerida.

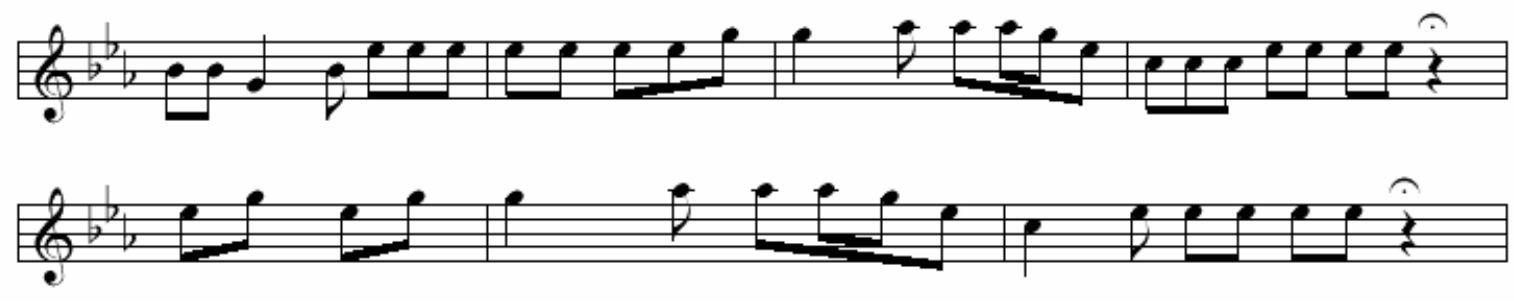



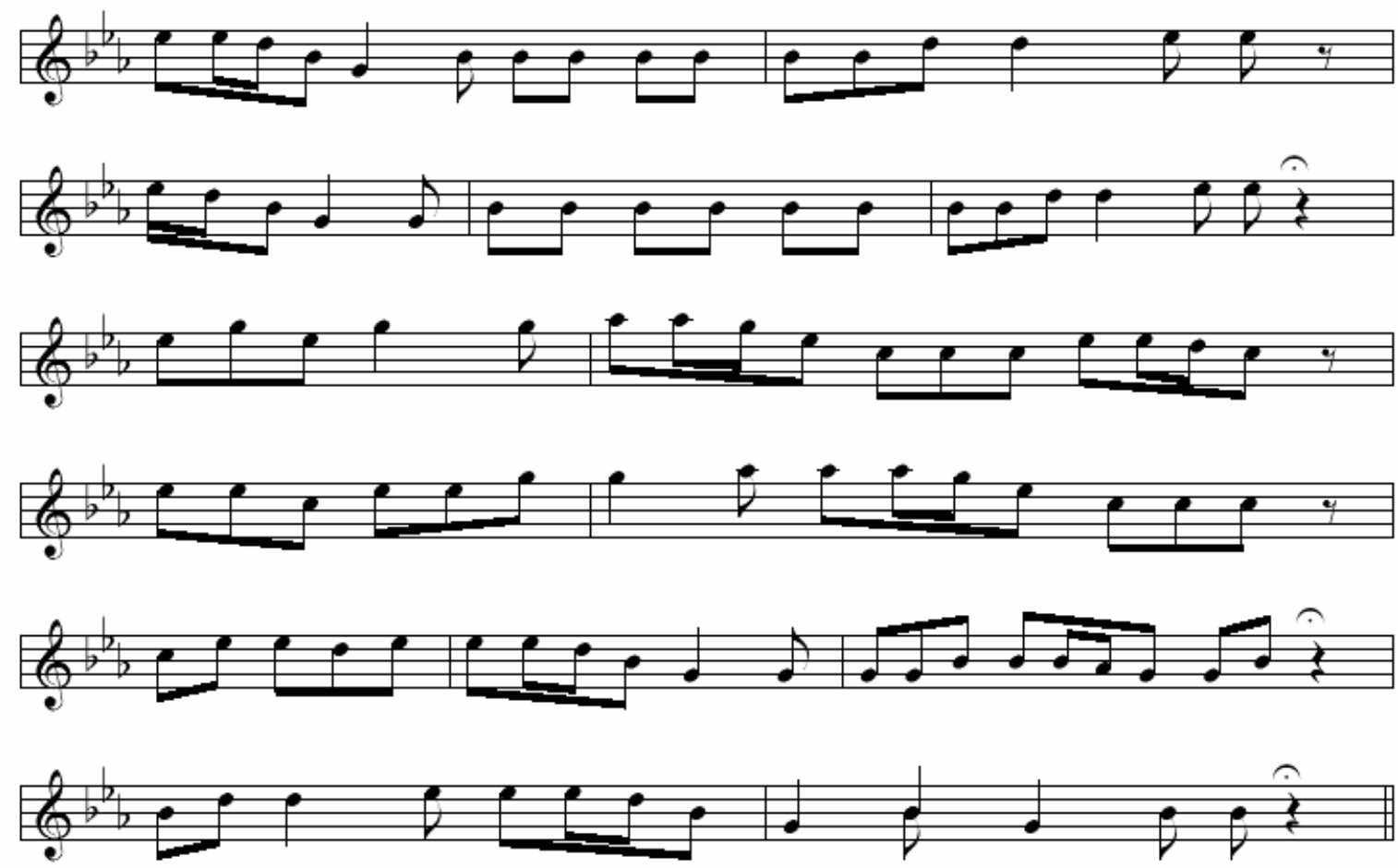

Kaks järgnevat laulu kuuluvad samuti St. Peterburgi Fonogramm-arhiivi kollektsiooni. Need on fonografeerinud Zinaida Evald Leningradis 8. aprillil 1937. aastal. Laulab Foma Danilov, 63-aastane, pärit Jokanga külast. Jevgeni Gippius jutustas J. Sarvele, et neil olnud Leningradis külas saami vanamees, “бывшийшаман”, kes kutsuti esitama laulu uuest elust. Sellest uusloomingulisest, kuid vanadest traditsioonilistest elementidest koostatud laulust on fonografeeritud mitu varianti. Kokku on Foma Danilov fonograafile laulnud 22 lauluvarianti, 17 erinevat laulu või motiivi (FA №№ 4516, CXLIV/1 kuni 4523, CXLIV/8). Osa laulude deshifreeringuid ladina ja slaavi shriftis koos reaaluste tõlgetega, mõned noodid ning informatsioon on kogutud mappi ФA II-28

Mõlemas laulus on tekst esitatud neljal real. Esimesel real deshifreerija kuuldeline silbitekst (vt selgitust laulu nr 1 juures). Teisel ja kolmandal real deshifreeringud Fonogramm-arhiivi mapist $\Phi$ A I-28. Need tekstid erinevad mitmes kohas tegelikult kõlavast tekstist. Liigsed silbid on paigutatud sulgudesse (J. S.). Arhiivikäsikirjas esinevad foneetilised märgid on püütud säilitada. Nende avamine jäägu filoloogide tööks. Neljandal real on antud sõnade eestikeelsed vasted arhiivimapis leiduva venekeelse tõlke alusel. 


\section{Külaliste laul}

Laulab Foma Danilov, 63 a Jokanga külast (turjasaami dialekt). Fonografeeris Zinaida Evald 8. aprillil 1937. а(Фонограмархив Пуикинского дома, Ленинград, 4523, CXLIV/8 No 1), teksti ja noodi dešifreerija teadmata.

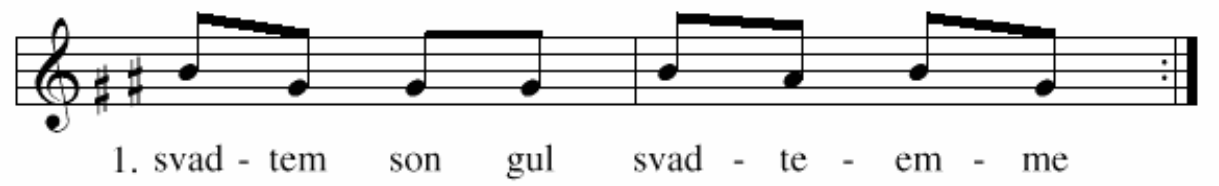

Näide koos teksti erinevate kirjapanekute ja tõlkega

Laulu sisuks on langude külaskäik (“Гостевал песнд"). Selle laulu struktuur on regivärsipärane. Üherealine meloodia kordub muutusteta. Viis on arhiivimapis ära toodud vaid esimese tekstirea juures. Tekstis esinevad refräänina korduvad neljasilbilised asemantilised lõigud.

\section{Pulmalaul}

Laulab Foma Danilov, 63 a. Jokanga külast (turjasaami dialekt). Fonografeeris Zinaida Evald 8. aprillil 1937. а. (Фонограмархив Пуикинского дома, Ленинград, 4522, CXLIV/6 No 1), teksti dešifreerija teadmata (Ф. A. П-28 No 9), noodistas Jaan Sarv.

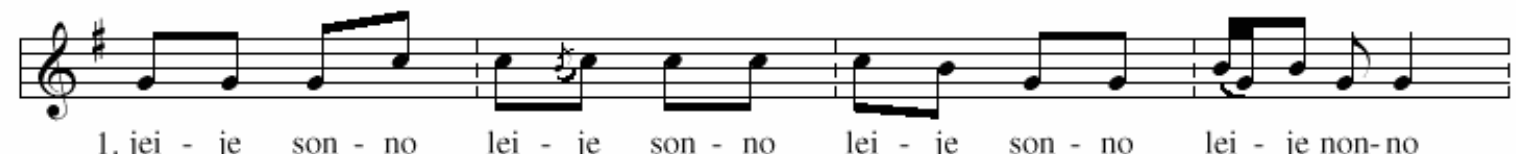

1. jei - je son - no lei - je son - no lei - je son - no lei - je non-no

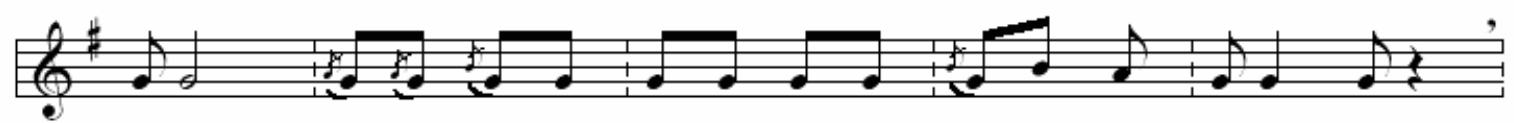

2. son-no gul- lo oi - je son-no lei - je gul-lo li son-no lei

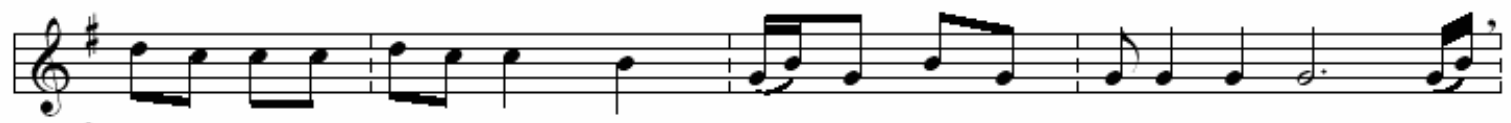

3. ak-ke-nem-me son-no ak - ka son - no li - je son-no lii - je gul

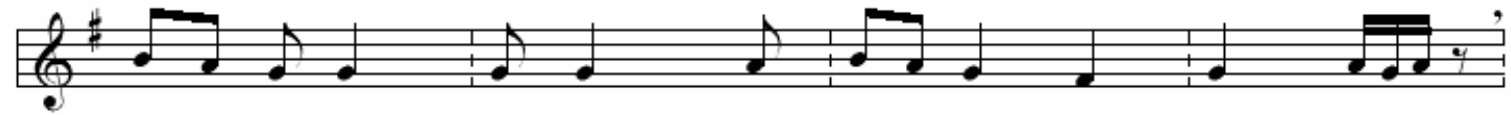

4. mi - ne gul- lo mi - ne nijt se-ni - hk - ka jed - tal - la 


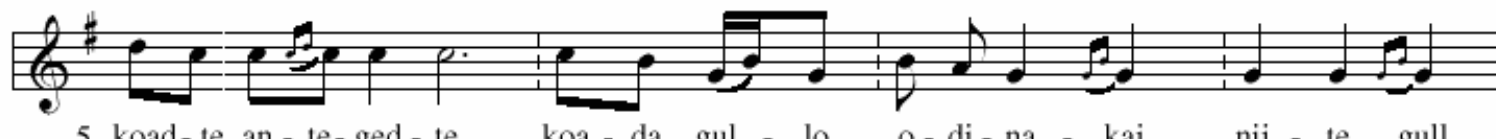

5. koad-te an-te-ged-te koa - da gul - lo o-di-na - kaj nij - te gull
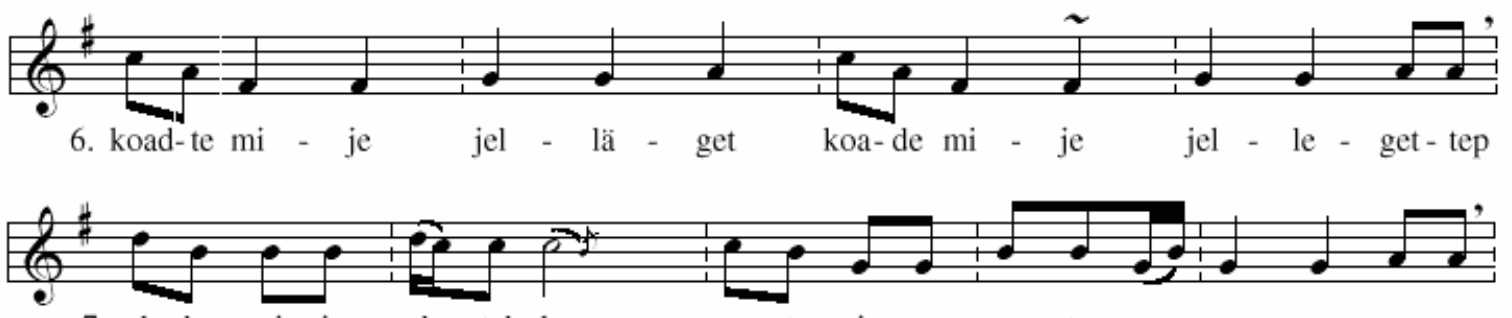

7. ak-ka - ai - jo el - tel-le an - te - nie an - te - ep an - te - ep - pe

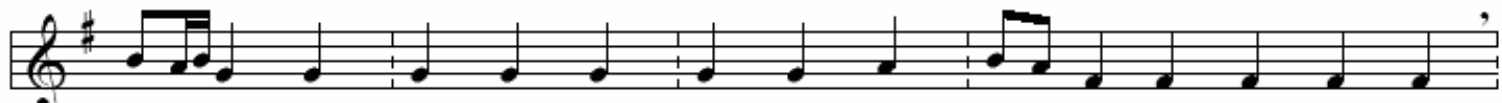

8. mi-na ket - san min - ne nijt min - ne nijt gul ij poa-res - mis - ke - de

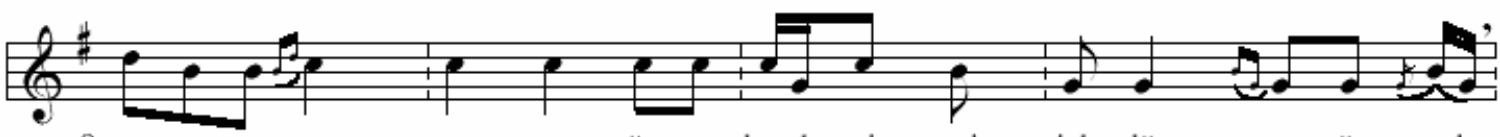

9. an - te-ep-pe an - te - äp-pe koadt ni pai jel - lä - get-täp guol

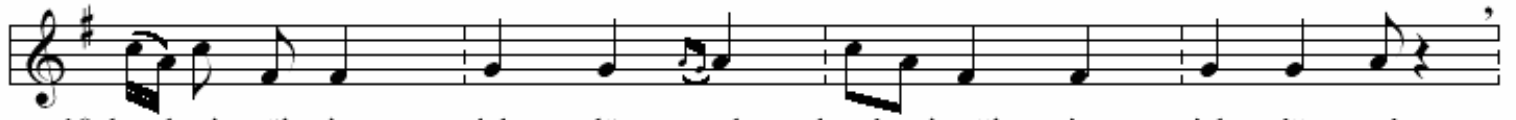

10. koadt ni päi - je jel - lä gul koadt ni päi - je jel - lä gul

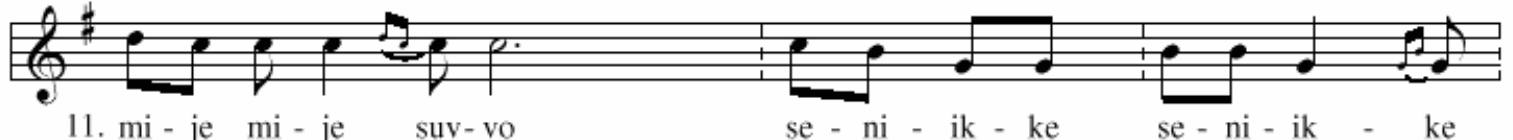

11. mi - je mi - je suv-vo se - ni - ik - ke se - ni - ik - ke

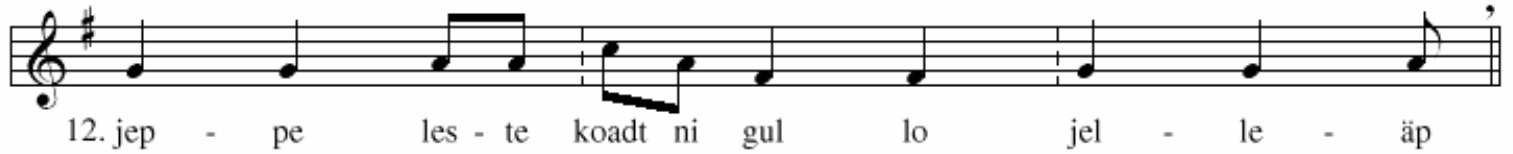

Näide koos teksti erinevate kirjapanekute ja tõlkega

Laulu sisuks on kosilaste esimene külaskäik. Seda olevat laulnud pruudi vanemad. Eraldi tasub veel kord rõhutada kosjateemaliste laulude rohkust ka 1977. aasta salvestiste seas. 


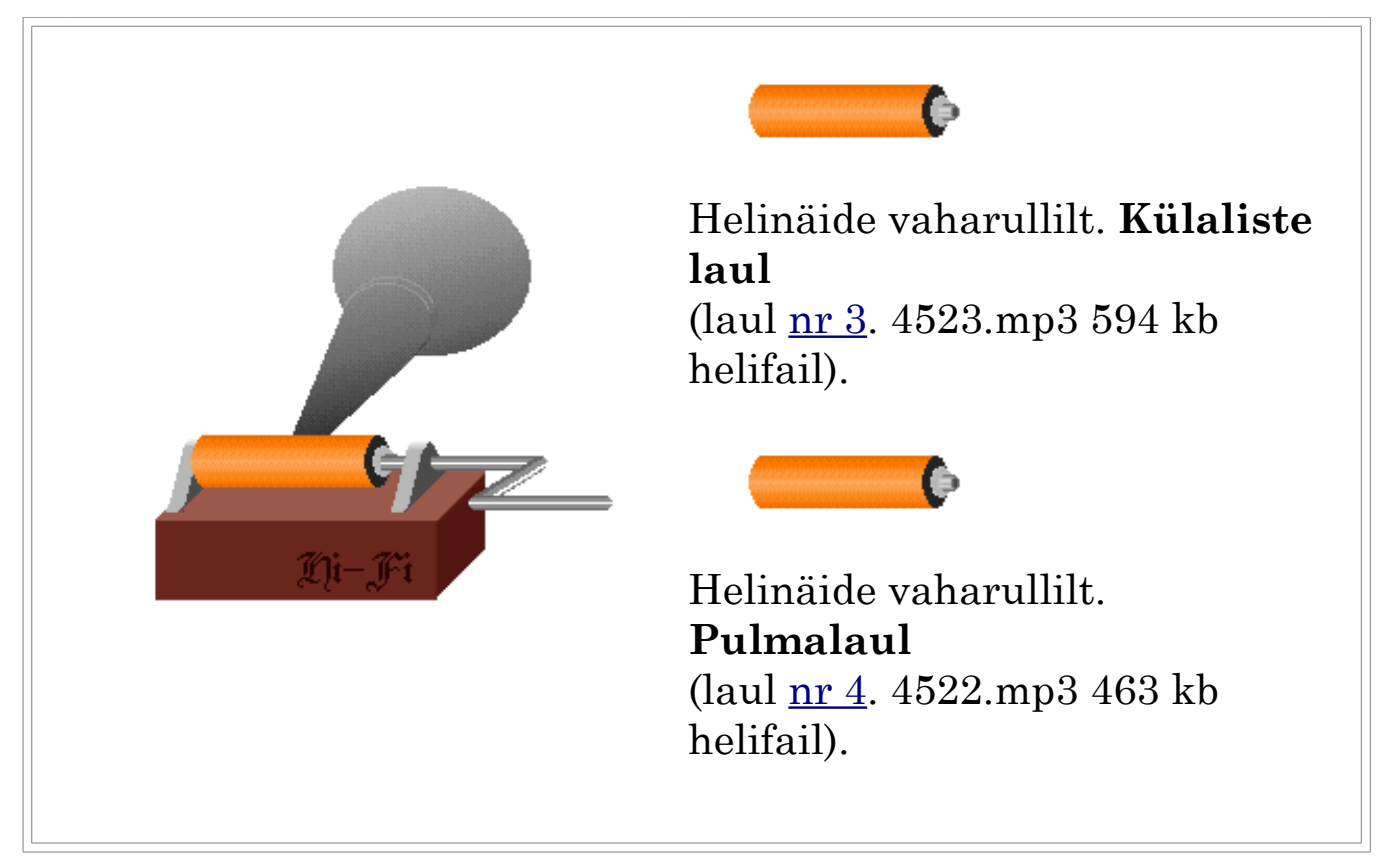

\section{Kirjandus}

Antonova, A. $1982=$ Sam bukvar. Leningrad.

KKS 1958 = Itkonen, T. I. Koltan- ja kuolanlapin sanakirja I, II. Helsinki.

Bernshtam, T. 1983 = Narodnaja kultura Pomorja $v$ XIX $i v$ natshale XX $v$. Leningrad. Homitsh, L. 1977 = Nentsõ $i$ komi Kolskovo poluostrova. Etnografitsheskie issledovanija Severo Zapada SSSR. Leningrad.

Sarv, J. 1986 = Pesni pro svatovstvo Kolskih saamov. Muzõka v svadebnom obrjade finno-ugrov $i$ sosednih narodov. Tallinn.

SES 1986 = Pihel, E. \& Pikamäe, A. Soome-eesti sõnaraamat. Tallinn.

SRS $1985=$ Sam - Rushsh Soagnehk. Saamsko-Russkii slovar. Pod red R. D. Kurutsh. Moskva.

Travina, I. $1987=$ Saamskie narodnõe pesni. Moskva.

VES 1975 = Arumaa, P. \& Pravdin, B. \& Veski, J. V. Vene-eesti sõnaraamat I, II. Tallinn. 


\section{Kommentaarid}

${ }^{1}$ argk - paastuvaba aeg, tal'v-argk - paastuvaba aeg talvel; tal'vargk-mana-jaanuar (KKS 1958: 16). Võrdle eesti argi.

${ }^{2}$ Ka Valge mere äärsed pomoorid, nagu on üldine Põhja-Vene traditsioonis, pidasid pulmi just talvel (Bernštam 1983: 163).

${ }^{8}$ Tegelikult kestab paast küll 40 päeva. Arvatavasti jutustaja eksitus.

${ }^{4}$ Enne komide sisserändamist Koola poolsaarele 1886. aastal olid saamide põdrakarjad väikesed, kuni paarkümmend looma pere kohta (Homitš 1977: 118).

'Saami sõna cuũŭm (SRS 1985: 336), siidt (KKS 1958: 496), norocm (VES 1975: 754) tähistab nii talveküla, selle juurde kuuluvat kogukonda kui ka kogukonnale kuuluvat territooriumi jõgede, järvede ja karjamaadega.

${ }^{6}$ cūppnэ̄ppm - mängumaja, cūpp - mäng (SRS 1985: 321), nэppm - elamu, maja, korter, tuba (SRS 1985: 280), võrdle ka soome pirtti - majake, onn (SES 1986: 219).

${ }^{7}$ Kasutatakse vene sõna cram, svatt (KKS 1958: 539), kuid on olemas ka oma sõna sȳy yъeũ - kosilane (SRS 1985: 332), suannjed - kosima (KKS 1958: 524), aga ka naime - kosjakaup (KKS 1958: $270)$.

${ }^{8}$ жэнэхь (SRS 1985: 88), ženeh (KKS 1958: 565) - kuni kosjadeni kasutatakse vene sõna.

${ }^{9}$ риссэм - kaelarihm (SRS 1985: 292), rissam - põdra kaelakella rihm (KKS 1958: 438). Võrdle eesti rihm. Võrdle ka ribpeh - rätik (KKS 1958: 441).

${ }^{10}$ коабсэсс - (SRS 1985: 113), käbsass - mõrsja (KKS 1958: 943), $k \overrightarrow{a b}$ - naine, abielunaine (KKS 1958: 100), -sass - liitsõna osa, mis tähistab tulevast sugulast (KKS 1958: 476).

${ }^{11}$ коангэсс, konogas - kuningas, peigmees pulmas (KKS 1958: 869). Vt ka коалхэсс-peigmees (SRS 1985: 115), коаллиэсь-kallis, kallim (SRS 1985: 115). 
${ }^{12}$ ша̄мми - abielunaise pidulik peakate õhukesest punasest kalevist, kaunistatud pärlitikandiga. Tanu kinnitatakse pähe punase lindiga või peene patsiga. Tugevdatud eesmine ülaosa ulatub nokana lauba kohale. Tanu peale pannakse ühevärviline siidrätik, sageli pikkade narmastega (SRS 1985: 409), $\breve{s} \bar{z} m \breve{s}$ - tanu (KKS 1958: 544). Samšek-kalla - tanu kaunistatud eesosa; šamsek-keddza tanu ülaosa, kõrge ettepoole kaarduv; zamšek-kr ̈̈̌̃av - tanu tagaosa pärlitikandiga, ka: pesser-krüžav, võrdle: vene бисер-кружева; zamšek-laokka - tanu päälagi; zamšek-veännta - tanu kõvendus, tehtud kalevist või vanast nahksaapast; zamške-vierge - tanu (Songelski e Suonikylä kolta materjal).

${ }^{18} \theta \bar{y} c c$-rahvuslik kott toiduainete, riiete ja jalanõude hoidmiseks. Ümmargune põhi on tavaliselt hülgenahast. Küljed tehakse pargitud põdranahast. Kott on kaunistatud mitmevärviliste kalevist kolmnurkadega või valgest nahast väljalõigatud ornamendiga (SRS 1985: 58). Vt ka vene кucá - nööriga kokku tõmmatud kott või kukkur (VES 1975: 409).

${ }^{14}$ лухххкемпэ̄ppm - itkumaja, lujhkem -itk, nutt (KKS 1958: 226).

${ }^{15} c u \overline{c c b}$ - tädi, isa vanem õde (SRS 1985: 322), võrdle lõunaeesti sõtse - isa õde.

${ }^{16}$ Oma sõnad puuduvad: sãravan - sarafan (KKS 1958: 474); kovta, кофma-jakk (KKS 1958: 154); fārtek, фapmyк - põll (KKS 1958: 32).

${ }^{17}$ пёрьвеськ, перев язка - neiu peakate, rõngakujuline, umbes $10 \mathrm{~cm}$ kõrge, pealt lahtine; õmmeldakse punasest kalevist, kaunistatakse pärlitikandiga. Selle peale pannakse tavaliselt siidrätik (SRS 1985: 254), pier'ves'k (KKS 1958: 357).

${ }^{18}$ ёрртемпэ̄ppm - keerutamismaja, ёрmъmэ - keerutama (SRS 1985: 87), jorrad - keerutama (KKS 1958: 69).

${ }^{19}$ яна, jāna - onu, ema vend (KKS 1958: 50). Siin: peiupoiss või isamees (дружка).

${ }^{20}$ костюм-тройка - täisülikond: püksid, vest, pintsak.

${ }^{21}$ Üleskirjutaja oli imestunud ja küsinud ema käest, kas mitte põder pulmarongi tegelaseks polnud. Ema aga kinnitanud, et just nimelt hobune.

22 чалльмчувэть - silmavalgust, чалльм - silm (SRS 1985: 387), чувв - valgus (SRS 1985: 400), tšal'mtšuovas - silma selgus, leiutasu (KKS 1958: 644). 
${ }^{28}$ пуалмэx, palmah, mitm palmhes't - palmik, abielunaise patsid (KKS 1958: 337).

${ }^{24}$ коаб - noorik, noor naine (SRS 1985: 112) (vt ka kommentaar 10). 